\title{
Lighting Characteristics Analysis on Sunshine Underground Garage
}

\author{
Wanying Qu, Wei Cheng and Fang Wang \\ College of Urban Construction, Wuhan University of Science \& Technology, Wuhan 430065, China
}

\begin{abstract}
In view of the problems existing in current underground garage, underground garage is considered in the design of Tongcheng Yuli district. The square PC plate dormer window of pyramidal of size $3 \times 3$ meters is set in the roadway above. After the completion of the building, the field measurement and questionnaire survey have been conducted in a synchronous way. The statistical method was used to analyze the data and the conclusions are as follows: the decline speed of the illumination is rapidly first and then slowly with increase of distance from the dormer, and is the exponential distribution. Lane illumination and distance is also exponentially. For side lighting, when luminance meets the minimum requirements of $30 \mathrm{~lx}$, a reasonable distance limit is at $\mathbf{1 4 . 3}$ meters, and the basic 2 column; While bilateral lighting, lighting distance is limited to 30 meters and is about 4 column size. The design points of the underground garage and the comfortable condition are analyzed. This paper will provide reference and basis for the design of the underground sunlight garage in the future.
\end{abstract}

Keywords-natural lighting; underground garage; dormer; luminance; exponential distribution

\section{INTRODUCTION}

TABLE I. POSSESSION OF PRIVATE VEHICLES

\begin{tabular}{|c|c|}
\hline Year & ten thousand \\
\hline 2006 & 2333.3 \\
\hline 2007 & 2876.2 \\
\hline 2008 & 3501.4 \\
\hline 2009 & 4574.9 \\
\hline 2010 & 5938.71 \\
\hline 2011 & 7326.79 \\
\hline 2012 & 8838.6 \\
\hline 2013 & 10501.68 \\
\hline 2014 & 12339.36 \\
\hline 2015 & 12435 \\
\hline
\end{tabular}

With the rapid development of urbanization, the lack of living space is caused by population growth and land expansion. Exploitment of the new living space become enormous Challenges today. The usage of underground space becomes the inevitable trend of urban development ${ }^{[1]}$. Underground garage is one of the types. With the improvement of living standards, as of 2015, the number of private car ownership has exceeded 124 million (Table 1). With more cars and limited resources on the ground, a large number of underground garage constructions have become inevitable. There are some negative psychological reactions in underground garage, such as darkness, damp, depression, uncomfortableness [2]. In order to make better use of underground space and reduce energy consumption, the introduction of daylight can make people eliminate many of the discomfort of the underground space ${ }^{[3,4]}$.

\section{UNDERGROUND GARAGE LIGHTING STANDARDS}

People's Republic of China industry standard Garage Architectural Design Standard (JGJ 100-2015), Underground Building Lighting Design Standard, Building Lighting Design Standard (GB 50033-2013) and Lighting of Indoor Work Places (GB/T 26189-2010), which have introduced degrees value of lighting need in garage, are not completely consistent. Lighting of Indoor Work Places (table 2). and Underground Building Lighting Design Standard (table 3). are more appropriate for the illumination of underground parking.

TABLE II. LIGHT STANDARD FOR PUBLIC CAR PARK

\begin{tabular}{|c|c|c|}
\hline Indoor parking ground & Lane & Park \\
\hline Luminance (lx) & 75 & 75 \\
\hline Dazzle degree & 25 & 28 \\
\hline
\end{tabular}

TABLE III. LIGHT STANDARD FOR UNDERGROUND GARAGE

\begin{tabular}{|c|c|c|c|}
\hline Category & Low & Middle & High \\
\hline Lane & 30 & 50 & 75 \\
\hline Park & 20 & 50 & 50 \\
\hline
\end{tabular}

\section{PROJECT INTRODUCTIONS}

Tongcheng Yuli district is located in the east coast of Xiushui River in Xianning City. It was built in 2014. Now there are many residents who live in there. Good environment and user-friendly design are praised by the residents. The comfort of underground garage is higher, in which lighting and ventilation are good throughout the year. 


\section{A. Planning Design Concept}

According to the overall planning ideas: "time for space, space for scale", lakeside landscape, sloping landscape and outdoor leisure space are given full consideration. In order to solve this extension of the actual land space, the parking spaces will be possible to move underground. Underground sunshine garage was brought up in the design. The design concept of natural lighting and ventilation, fully meet the needs of comfortable thermal environment and light environment in underground space, and reflect on the care of the occupants and create a livable community space.

\section{B. Parking Design}

This project has a good external traffic conditions. It is near the city road in the east of the base. There are two main entrances. The main roads are arranged in a circle and land utilization rate is high. The area of every motor vehicle parking is required 200 square meters, and high-rise residential is required 0.6 parking spaces every household. There are a total of 185 parking spaces in a combination of outdoor and underground sunshine garage.

\section{Underground Garage Design}

There are 125 parking spaces in the underground sunshine garage. And there are a total of 5 high-rise tower buildings which are $\mathrm{T}$ type and shear wall structure. Therefore the surrounding parking utilization rate is low. Underground space under the center green ground can be used as parking spaces.

One-parking- space is designed by $2400 * 5000 \mathrm{~mm}$ in the center column. The column section width is $500 \mathrm{~mm}$. According to the Principle of increasing column spacing, fewer columns and more parking, three-car-parking per column spacing are arranged. The parking column spacing is calculated by $7800 * 5000 \mathrm{~mm}$. Considered the minimum lane width of $5000 \mathrm{~mm}$, which is the optimal. For structure processing requirements, there is two-car-design with $5400 * 5000 \mathrm{~mm}$ and single- parking- space with $3600 * 5000$ $\mathrm{mm}$. the edge of the basement is in parallel with the superstructure and the underground sunshine garage is simple and square.

\section{The Lighting AND Ventilation Design of UNDERGROUND GARAGE}

\section{A. Analysis of Underground Skylight}

When this project design of underground garage roof has completed, it was praised by the residents. They believe that the garage entrance and skylight design can effectively solve the sense of closure of underground construction. The ground and the underground can link together by top lighting design, which make people feel comfortable and safe underground. The design of the roof of the underground garage, which can be used for lighting and ventilation, can create a comfortable thermal environment (Figure I). On July 9, in2016, when the outdoor temperature is $28-34{ }^{\circ} \mathrm{C}$, the underground garage contain at constant temperature of $22-26{ }^{\circ} \mathrm{C}$.
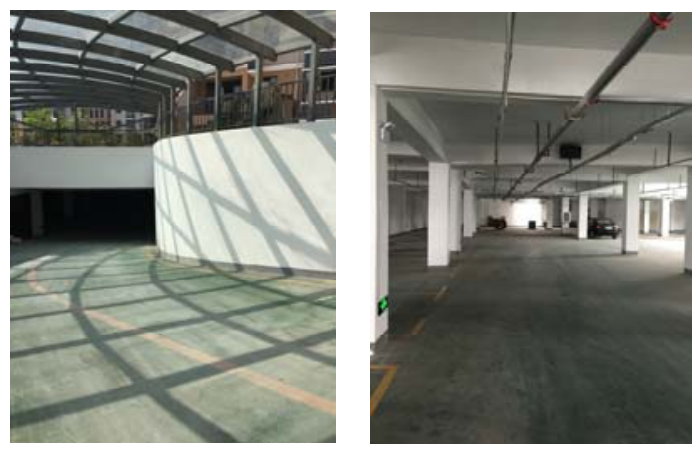

FIGURE I. NATURAL LIGHTING

\section{B. Influencing Factors of Lighting in Underground Skylight}

The main factors which affect the lighting of the underground skylight are the shape of the hole, the form of the lighting, window area ratio, the material of the skylight and the layout of the skylight. The shape of the hole has an influence on the lighting coefficient of underground garage. When window area ratio is the same, Average daylight factor of each hole is different: circular < triangle $<$ square. With different types of lighting cover, the lighting coefficient is different: Plate type < arched dome shape < pyramid shape. When the material of the lighting cover is different, the lighting coefficient is different too: the laminated glass < transparent glass $<$ toughened glass $=\mathrm{PC}$ board. When the skylight is well-distributed, the effect is the better.

In Yuli district design, using PC plate window with pyramid square plane, is excellent on lighting effect (Figure II).
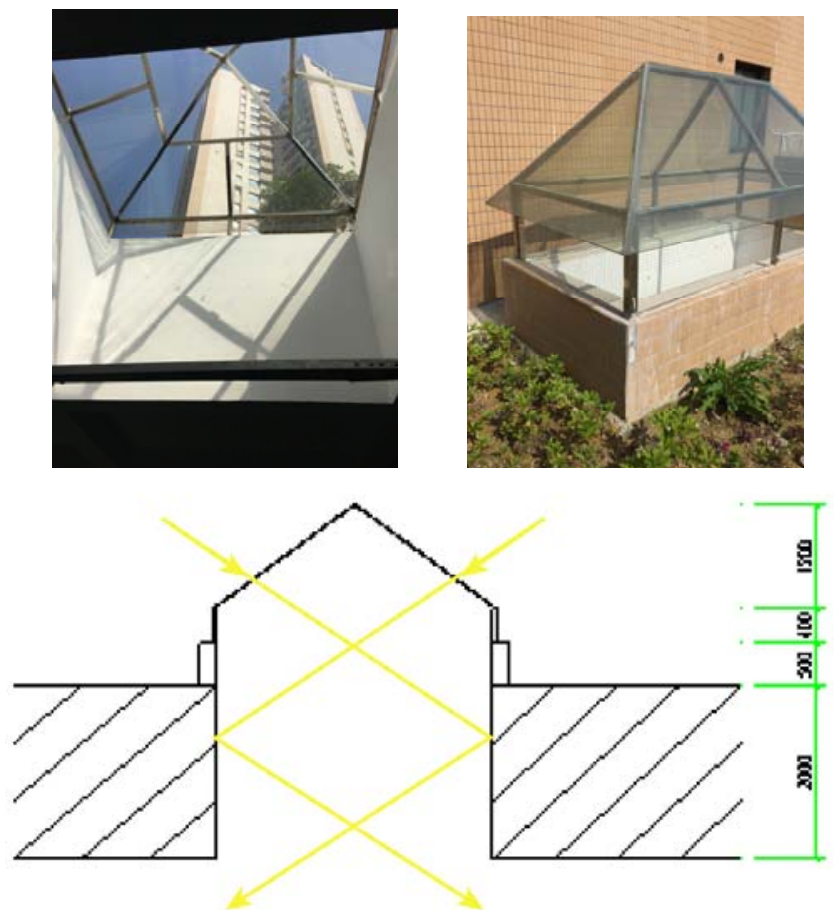

FIGURE II. DORMER DESIGN 


\section{CONCLUSIONS}

A. At present, in a large number of high-rise shear wall constructions, the parking problem can be solved by using the underground space below the courtyard. Reasonable lighting design can solve the problems of the dark, damp, depressed, claustrophobic and so on in the underground garage.

B. Using PC plate window with pyramid square plane, is excellent on lighting effect 4.3 Window area ratio of $1 / 50$ can meet the lighting requirements. With $3 \times 3$ meters above the roadway roof and a distance of 30 meters in the center line all meet the lighting requirements of underground garage.

\section{ACKNOWLEDGEMENTS}

Foundation Item: Science and Technology Research Program of Hubei Minister of Education of China ((Project Number: Q20151107); Major project of Philosophy and Social Sciences Research by Hubei Minister of Education of China (Project Number: 17D018).

\section{REFERENCES}

[1] Wu Wei.Design of natural lighting technology for underground skylight[D], Master Thesis of Southeast University,2008

[2] Yang Yanmei, Yang Chunyu. Study on natural lighting mode of underground garage[J], Lamps and lighting, 2014, 38 (4)

[3] Beltran L O, Lee E S, Selkowitz S E.Advanced optical daylighting system:light shelves and light pipes[A]. Annual Conference[C], Cleveland, OH, 1996.

[4] Floyd David B, Parker Danny S. Field commissioning of a daylight-dimming lighting $\quad$ system http://www.fsec.ucf.edu/bldg./pubs/pf283. 